\title{
Aproximaciones a la figura materna a través de las narrativas de feminidad de mujeres jóvenes de clase media emergente en Lima ${ }^{1}$
}

\author{
Ángela Paola Mera Mejía \\ Pontificia Universidad Católica del Perú \\ amera@pucp.pe
}

RESUMEN

En este articulo se describen y analizan las representaciones de las figuras maternas en las narrativas de feminidad en cinco casos de mujeres jóvenes de clase media emergente en Lima, Perú. Para ello, se realizaron entrevistas a profundidad entre 2017 y 2018, y se utilizó un muestreo en bola de nieve para encontrar a personas que cumplieran con estos criterios. Se encontró que la representación materna es importante de una manera particular en el paso generacional madre-hija de este estrato socioeconómico, pues no solo se transmiten los modelos de feminidades, sino también las aspiraciones de clase. Se da cuenta de la generación de estas nuevas narrativas de feminidad usando el concepto de discurso herético de Pierre Bourdieu.

Palabras clave: maternidades, feminidades, movilidad social, mujeres jóvenes, clase media emergente.

\footnotetext{
1 Este artículo se elaboró con materiales que forman parte de la tesis de licenciatura en sociología que sustentaré próximamente en la Pontificia Universidad Católica del Perú.
} 


\title{
Approaches to the mother figure through the narratives of femininity of young middle-class women emerging in Lima
}

\author{
SUMMARY
}

This article describes and analyzes the representations of maternal figures in femininity narratives in five cases of emerging middleclass young women in Lima, Peru. To do so, in-depth interviews were conducted between 2017 and 2018, and a snowball sampling technique was used to find people who met these criteria.

The article finds that, for women of this socio-economic status, maternal representation takes a particular form in the motherdaughter generational handover. Not only are femininity models transmitted, but also class aspirations. The generation of these new femininity narratives is analyzed through the concept of heretical discourse developed by Pierre Bourdieu.

Keywords: maternity, femininity, social mobility, young women, new middle class. 


\section{INTRODUCCIÓN}

Durante la segunda mitad del siglo pasado se desarrollaron en el Perú una serie de procesos que reconfiguraron la estructura socioeconómica y los marcos culturales. Hacia la década de 1980, Quijano menciona que procesos como la urbanización, industrialización, migración hacia las urbes y alfabetización fueron claves en la formación de nuevos sujetos populares urbanos (citado por Pajuelo, 2002, p. 2). Posteriormente, Toche menciona que en la década de 1990 se profundiza la brecha urbano-rural, y Lima llega a albergar a la tercera parte de la población peruana (2009). Asimismo, el conflicto armado interno y la liberalización del aparato estatal evidenciaron la violencia estructural y la acentuada desconfianza en las instituciones (Toche, 2009). En este contexto, como señala Rivera, la educación y el autoempleo «se convirtieron en fuentes de precario, aunque promisorio, bienestar» (1993, p. 19). De esta manera, siguió creciendo una gran masa popular urbana que formaría parte de una nueva y heterogénea clase media. Según Toche, la clase media se expandió y se hizo necesario tipificarla según su composición:

Una clase media tradicional, vinculada al imaginario dual colonial y a un temprano impulso modernizador, que asigna una alta valoración al gasto como inversión para el mantenimiento o la apariencia de un estilo de vida; una clase media consolidada, producto de la expansión urbana y de la segunda reforma universitaria, que posibilitó su desarrollo como élite intelectual y tecnócrata (Portocarrero, 1998; Fuller, 2002); y una clase media emergente, producto de las migraciones masivas, de la redefinición del espacio urbano y de los nuevos usos del capital económico y relacional (2009, p. 151).

En este trabajo se abordarán las maneras de actuar, pensar y sentir las mujeres de este último grupo. Fuller señala, para el caso peruano, que desde la década de 1980 hay mayor igualdad jurídica entre hombres y mujeres, se masifican los métodos anticonceptivos, se da una mejor inserción en el mercado laboral de las 
mujeres, las brechas de educación se reducen, y algunos imaginarios sobre las estructuras familiares se ven cuestionados (1998). Asimismo, según Rivera, las mujeres migrantes no solo pasaron del campo a la ciudad, sino también de los roles tradicionales domésticos hacia el mercado laboral urbano (1993, p. 20). En ese sentido, Ruiz-Bravo indica que las mujeres se enfrentaron no solo a las escasas opciones dentro del mercado laboral, sino con el grupo familiar y los roles que se esperaba fuesen cumplidos (2003). De esta manera, los procesos indicados posibilitaron nuevas maneras de ser mujer en el Perú desde esos años hasta la actualidad, y por lo tanto, nuevas actorías y relaciones sociales en diferentes ámbitos y niveles.

En esta investigación se analizan las narrativas de feminidad de mujeres de clases medias emergentes. Desde los estudios de movilidad social se suele asociar la jefatura de familia y el rol proveedor con una figura masculina. Sin embargo, pese a contar con un ingreso menor en un 30 por ciento con respecto a sus pares varones, las mujeres son jefas de hogar en un 54 por ciento de los casos, según una encuesta realizada por el Banco Interamericano de Desarrollo y Arellano Marketing (2016). Si bien es cierto que ha habido intentos de incluir la asimetría de género en el estudio de la desigualdad y de la movilidad social, se reconoce que no es suficiente y que son necesarios estudios que aborden las estrategias con las que se he enfrentado la desigualdad en el paso de madres a hijas (Solís, 2016). En este trabajo se enfatiza la relación de figura materna con las narrativas de género en la relación madre-hija, en el marco de las estrategias que se recrean.

\section{APROXIMACIONES CONCEPTUALES}

Desde las ciencias sociales, se ha teorizado sobre cómo las nociones de sexo y género configuran las estructuras y las relaciones sociales. La feminidad es entendida por Lagarde como "atributos naturales, eternos y ahistóricos, inherentes al género y a cada mujer» (1990, p. 3). La autora menciona que estos atributos moldean las maneras de actuar, sentir y pensar de las mujeres, pero que es imposible que una mujer cumpla con la sobrecarga de imperativos que se le atribuyen, la cual generaría conflictos y dificultades. Lagarde sugiere que las pistas para analizar los cambios en las feminidades serían la maternidad y la sexualidad, como maneras de entender las recreaciones de las subjetividades, el cuerpo y el erotismo (1990).

A través de la sexualidad (heterosexual), se logra ser madre, y así se compone el continuum intergeneracional de feminidad. Kornreich (citada por Zea, 2015) 
señala, sin embargo, que es posible transmitir la cultura y la fuerza de las mujeres a través de la línea materna. Esta valoración no significa que se desarrolle un mandato estricto de reproducción de una feminidad, sino que representa un recurso posibilitador de nuevas vivencias e identificaciones de género.

En ese sentido, estas identificaciones, representaciones y narrativas se hacen posibles a través de relaciones conformadas en los diferentes espacios de socialización. Estas relaciones estructurales están atravesadas por la división sexual y la división moral del trabajo, pues no solo son pensadas como biológicamente naturales, sino como moralmente esperables (Rivers, citada por Zea, 2015). Según la autora, las mujeres se han encargado históricamente de las tareas reproductivas del cuidado y del ámbito doméstico, y los varones de la provisión y del ámbito público.

En esta línea, se sostiene que el rol de cuidado configura «un carácter múltiple, contradictorio y simultáneo» (Arango y Molinier, 2011, p. 95) en las identidades de las mujeres como agentes sociales. Esto se debe a una doble presencia de las mujeres: en la familia y en el mercado. Este entramado de situaciones trae también significados contradictorios, negociaciones y tensiones subjetivas debido a esta doble carga.

Esta dificultad de las mujeres para constituirse en sujetos supone una «impotencia aprendida» (Lagarde, 1990, p. 141). En ese sentido, los roles domésticos y de cuidado son un factor clave para la constitución de las feminidades. Asimismo, señala que el ser profesional o entrar al campo laboral solo sería considerado virtuoso si no hace peligrar el rol de madresposa.

La maternidad, como se señaló anteriormente, es uno de los de los hitos que configuran las feminidades en las trayectorias de vida de las mujeres. Lipovetsky, en esa línea, también indica que la maternidad dota de sentido a la vida de las mujeres, pues se saben indispensables en la vida doméstica y privada. Este tipo de poder y autonomía, según el autor, se asienta en la relación con los hijos (1999). Por ello, considera que, aunque las mujeres ingresen al ámbito público a través de la profesionalización y el trabajo, parecen no querer abandonar la esfera privada (Lipovetsky, citado por Pariona, 2016). Sin embargo, el trabajo no deja de ser un medio de autorrealización. Según este autor, el trabajo es una de las bases para la identidad femenina actual (1999). El trabajo no solo significa la entrada a la esfera pública, sino el fruto de una conquista conseguida por varias generaciones de mujeres (San Pedro et al., citados por Pariona, 2016). Así, el proyecto de vida, según D'Angelo (citado por Pariona, 2016), se forjaría sobre estas bases privadas, como la familia, y públicas, como la profesionalización y el trabajo. El proyecto 
de vida, entonces, es el modelo ideal de lo que los individuos esperan y quieren ser y hacer en el futuro. Este se sustenta en aspectos subjetivos y sociales, en el marco de posibilidades y recursos que se encuentran en el contexto. Además, el proyecto de vida también implica una capacidad autorreflexiva sobre el propio proyecto y personalidad (2014).

En reflexiones posteriores, Lagarde (2000) acuña el término «sincretismo de género», para hacer referencia a las feminidades constituidas a través de estas múltiples tensiones. Según la autora, el sincretismo de género «nos obliga a movernos entre lo público y lo privado, entre la tradición y la modernidad, con algunos poderes y derechos limitados y, al mismo tiempo, con déficit y brechas sociales».

Las valorizaciones sobre las feminidades se encuentran en un período de cambios en el que estas se van reescribiendo. Sin embargo, no tener algo fijo y estar siempre pendiente de lo que sería correcto o no, conduce a experimentar sensaciones, afectos y pensamientos de escisión (Lagarde, 2000, p. 37). En esta línea, cada mujer debe enfrentar en el mundo las contradicciones entre la modernidad y tradición y, al mismo tiempo, sus propias contradicciones internas producto de esta escisión entre valores, estilos y decisiones personales basadas en la dimensión subjetiva, tradicional o moderna, y en el modo de vivir, que reproducen o replican las contradicciones externas.

En síntesis, como señala Butler (2007), las relaciones de género no son ni continuas ni coherentes, pues la unidad ontológica de la mujer ha sido concebida para facilitar posicionamientos políticos y académicos. Así, por la intersección de diversos ejes, no todas las mujeres atraviesan las mismas experiencias de género.

\section{MOVILIDAD SOCIAL Y DESIGUALDAD}

Por otro lado, los estudios sobre movilidad social buscan entender las posibilidades de cambios individuales y colectivos en las condiciones de los sujetos dentro de la estructura social. Dalle (2016) señala que la desigualdad social no se constituye por la posición social en sí misma, sino por los vínculos sociales. De esta manera, se debe profundizar en las pautas de socialización, es decir, en las maneras en que los entornos institucionales definen el conjunto de roles, interacciones y estilos de vida. Así, se involucran la agencia y las expectativas de las personas enmarcadas en sus estilos de vida. Por ello, las metodologías que se aproximan a las biografías nos permiten entender los mecanismos sociales de reproducción 
y movilidad social (Dalle, 2016), pues abarcan las tres dimensiones sociológicas a partir de las narrativas de, en este caso, nuestras entrevistadas.

La manera en la que los sujetos explican sus trayectorias biográficas, así como las narrativas de movilidad social intergeneracional, son importantes para analizar la apertura y el cierre de oportunidades, así como la agencia desplegada (Dalle, 2016). La movilidad social ascendente intergeneracional es entendida «como un ascenso de las personas hacia una posición de clase más alta en relación con su origen, es una medida tanto de las oportunidades ocupacionales y educativas estructurales que brinda una sociedad como del nivel de (des)igualdad con que se distribuyen dichas oportunidades entre personas de orígenes sociales distintos» (p. 73).

En el Perú, los intentos por entender la desigualdad se han desarrollado a través del concepto de clase. Esta investigación tiene como sujeto de estudio a mujeres de clase media emergente y sus experiencias de desigualdad. Para ello, es importante profundizar sobre el concepto de clase media emergente. Eduardo Toche encuentra que esta nueva clase media no quiere parecerse ni ser como la clase media tradicional, sino que, en medio de tensiones, disputas, y espacios compartidos, crea en paralelo sus propios modos de vida esperables. Asimismo, este sector se caracterizaría por una gran desconfianza en los canales institucionales de reproducción y en las posibilidades de movilidad social (Toche, 2009).

Por otro lado, este habitus de clase media emergente se vincula con los procesos y con los cambios estructurales en el sector educativo. A diferencia de la clase tradicional (que piensa la educación como meta y símbolo de estatus), la clase media emergente, según Toche, tiene la concepción de la educación como herramienta para mejorar las condiciones económicas de la familia. En esta línea, Luis Reygadas (2008) menciona que los estudios de género han logrado una contribución fundamental para entender las resistencias a la desigualdad. Señala que en las últimas décadas se han erosionado muchos monopolios masculinos y ello ha contribuido a una mayor equidad en las relaciones entre lo masculino y lo femenino. Así, se toma el género también como un eje posibilitador de clase, pues si bien se podría plantear la dicotomía explotadores / explotados, o dominantes / dominados, estos grupos viven juntos en la cotidianidad y no se presenta una distinción tan clara en sus experiencias. Por ello es necesario vincular los estudios de la desigualdad con los estudios de género, pues se rastrean de manera más precisa las desigualdades que se originan a través del género como categoría estructural, así como las trayectorias y desigualdades intracategoriales en esta. 


\section{METODOLOGÍA}

Aunque se tomó en cuenta una cohorte de edad determinado, esto no significa, como señala Manheim (citado por Brunet y Pizzi, 2013), que estas personas conformen un grupo homogéneo. Lo que se buscó es que fuesen estudiantes universitarias, quienes empezaron sus estudios superiores meses después de terminar la educación básica. Como señala Bourdieu (citado por Brunet y Pizzi, 2013), la conceptualización de juventud deviene de un estadio social diferenciado. Vincular la juventud con la trayectoria universitaria del pregrado las hace parte de un grupo común en la estructura social.

Se aborda el problema de investigación desde la narrativa biográfica. Esta permite a los sujetos dibujar y replantearse sus propias trayectorias (Dalle, 2016), dando inteligibilidad a las narrativas de feminidad que atraviesan sus experiencias y valoraciones. En ese sentido, a través de las narrativas se puede rastrear un «discurso extraordinario», es decir, «una oportunidad para explicarse, en el sentido más completo del término: de construir su propio punto de vista sobre sí mismos y el mundo» (Bourdieu, 1999, p. 536). En este marco, buscamos que la informante lograra articular y justificar discursos sobre sí misma que no había logrado hacer antes.

Se realizaron cinco entrevistas en profundidad, en las que se relatan trayectorias de vida. La reconstrucción de los sujetos de estudio sobre sus vivencias de género, categorizándolas y relacionándolas entre ellas y con las de sus madres, es un ejercicio reflexivo que devela sus posiciones frente a las experiencias vividas y a las posibles feminidades. Como señala Flick (2007), la narración «imita a la vida», a través de lo cual se construye un raciocinio activo de la experiencia vivida.

Se eligió a las entrevistadas a través de bola de nieve, el cual, según MartínezSalgado, permite identificar los casos de interés a través de que un informante inicial refiere a otros candidatos de informantes con características que se consideren similares (2011, p. 616).

Las variables consideradas en la elección de las entrevistadas buscan dar cuenta de procesos de movilidad social ascendente, y la concomitante incursión de las mujeres de la familia a los estudios superiores. Para caracterizar los procesos de movilidad social se ha considerado entrevistar a mujeres de dieciocho a veintitrés años, quienes tienen acceso a los estudios universitarios, a diferencia de sus madres, quienes no han tenido acceso a ellos a la misma edad (inmediatamente después del colegio), o que han tenido que trabajar para luego acceder a ellos.

En ese sentido, el concepto de discurso herético propuesto por Bourdieu (2001) y abordado por otros autores desde una mirada latinoamericana (Arango, 
2002) permite abordar las condiciones en las que estas experiencias y trayectorias configuran nuevas narrativas de feminidad. El autor propone que las resistencias heréticas son posibles en la medida que exista una crisis objetiva y un capital crítico acumulado. En esta investigación, se describen y analizan ambos factores y la manera en la que se construye un discurso herético en el marco de los que se denomina un habitus de resistencia.

\section{NUEVAS NARRATIVAS DE FEMINIDAD A TRAVÉS GENERACIÓN DE DISCURSOS HERÉTICOS}

Ahora bien, ¿se podría sugerir la existencia de nuevos modelos de feminidad? ¿Las narrativas encontradas darían pie a otras representaciones de mujer? A la luz de la noción de discurso herético, planteada por Bourdieu, se pueden explicar espacios de fuga o márgenes de libertad para que, a través de ciertas condiciones generadas en el espacio social, se quiebren los órdenes establecidos y, en ese sentido, se abran posibilidades en la reproducción social, en términos de clase y de género (Arango, 2002). En este marco, daremos cuenta de tensiones con relación al género y a la trayectoria familiar de movilidad social. Estas tensiones se enfrentan a través de narrativas de resistencia que se forjan en el plano familiar, particularmente en la línea materna. Ahora bien, estas narrativas de resistencias no se generan de manera automática, sino que son posibles gracias a un entramado deliberativo que despliegan las agentes.

A través del discurso herético se crean posibilidades que no se cristalizan necesariamente en estructuras institucionales. Estas posibilidades se encuentran en constante tensión, y forman parte de luchas simbólicas que se libran a través del poder-saber. En esta línea, los discursos heréticos configuran marcos de referencia alternativos a los tradicionales. Así, en la experiencia de la palabra, entonces, se traducen transformaciones que devienen en narrativas de feminidad con ciertos quiebres en relación con los paradigmas de género tradicionales. Según Arango (2002), para generar una ruptura herética con las disposiciones y representaciones del orden establecido se debe producir una coincidencia entre una crisis objetiva y un discurso critico.

En esta investigación se han encontrado casos que presentan crisis objetivas en cada trayectoria de vida. Sin embargo, el hilo conductor han sido las experiencias del género y de movilidad social. En general, la experiencia de ser mujer para las madres y el enfrentamiento a algunas narrativas que frenaban su entrada al campo laboral o profesional, así como para las hijas, quienes han experimentado 
tensiones en torno a su cuerpo y sexualidad, generan crisis objetivas alrededor de los esquemas tradicionales de género. Asimismo, estas experiencias y discursos se cruzan con la posición social en términos de clase, en las que experimentan tensiones alrededor de los deseos, aspiraciones y trayectorias de movilidad social ascendente. Entonces, se evidencia que existen constantes tensiones entre las narrativas tradicionales y modernas sobre la feminidad.

En ese sentido, los discursos heréticos atraviesan la línea materna desde las abuelas. En el caso de Inamabari, destaca una historia intergeneracional de movilidad social. Aquí la crisis objetiva se relaciona con las condiciones del contexto de su abuela, en el que era más difícil acumular recursos económicos. La competencia crítica, en ese sentido, se genera cuando la abuela decide trasladarse a otros espacios y generar recursos económicos a través de sus negocios, incluso pese a que su esposo no tuviera las mismas proyecciones:

Mi abuela es la que hizo todo, la que hizo que mis tíos fueran lo que fuesen, porque sin ella, sin ella probablemente todos mis tíos seguirían en Huancayo. Porque eso era lo que se había proyectado mi abuelo: a tener una casa chiquita por ahí en Huancayo y que iba a trabajar a la Oroya en la mina, y se iba y así y todos se quedaban ahí en Huancayo sin hacer nada más que eso. Pero mi abuela quiso tener propiedades, quiso atender negocios, les pagó la educación hasta que ella consideró que debía apoyarlos (Inamabari, 22 años).

Asimismo, esta entrevistada plantea la importancia de las decisiones tomadas por la abuela y la madre en la trayectoria biográfica que experimenta. Inamabari enfatiza la línea materna como posibilitadora de los recursos económicos y culturales que actualmente posee, en comparación a los abuelos o el padre. Además, estos recursos no solo se refieren a posesiones o recursos materiales, sino que constituyen parte de su identidad actual.

Pero de lo que sí estoy segura, es que yo sé que, si mi mamá se hubiera quedado con mi papá, o mi abuela le hubiera hecho caso a mi abuelo, yo probablemente no estaría acá. Yo quizás ni existiría, pero si existiese, de repente ni estaría estudiando, o de repente estaría trabajando en algo chiquito para ayudar a mi familia. Pero lo que tengo económicamente es gracias a mi abuela, ella. Lo que tengo académicamente es de mi mamá. Pero si mi abuela no se hubiera puesto las pilas cuando era joven, ninguno de mis tíos lo hubiera logrado, ni siquiera venir a Lima (Inamabari, 22 años).

La entrevistada recalca que las mujeres de su familia, como su madre o sus tías, han experimentado muchas situaciones difíciles asociadas con la esfera económica y la familiar en el horizonte de dar a sus hijos estudios universitarios. Así también, 
Inamabari destaca que sus tías hayan logrado romper con las parejas con quienes habían formado familias de composición tradicional. En ese sentido, recalca que a las mujeres de su familia les va mejor en comparación con los hombres. Inamabari narra que esta diferencia no solo se encuentra en la esfera económica, sino que se asienta en la familiar y emocional. Aquí identificamos una competencia crítica respecto del modelo de familia, pues señala que las mujeres de su familia han tomado decisiones que han roto con lo que tradicionalmente se esperaría en ese aspecto. La entrevistada relaciona estas decisiones con la posibilidad de alcanzar los recursos económicos y culturales para sus familias justamente al zanjar con relaciones que denominan como tóxicas. En ese sentido, compara a los hombres de su familia, quienes no saben lidiar con sus emociones ni con sus recursos económicos.

Mi mamá y mi tía son mujeres extremadamente fuertes que no han necesitado, se han dado cuenta rápido de que esta idea de la familia feliz con la mamá y papá y los hijitos no es para ellas. Lo que han querido comprar, lo han comprado. Si han querido que sus hijas estén en la universidad, están haciendo que sus hijos estudian en la universidad, solas. [...]. Entonces este a modo comparativo, mis tíos están emocionalmente un desastre, también en los negocios es un desastre [...]. Es que es muy fácil cagarla para los hombres, no sé; yo creo que... es que somos más bacanes, es que yo creo que esto de la inteligencia emocional es bien importante: esto de aprender a sostenerte, aprender a salir adelante, yo siento que es algo que en general no les enseñan a tener inteligencia emocional. Muy racionales y muy todo, pero cuando algo nos les sale bien se van al hoyo y no saben cómo levantarse. En cambio, las mujeres estamos bien acostumbradas a eso, ¿no? y con eso, y con todo lo que nos pasa, salimos, seguimos, o sea, y también es muy fuerte esto de ser sororas entre nosotras, o sea mi mamá habrá podido ser un desastre en esto de las relaciones, pero nunca me ha dejado sola (Inamabari, 22 años).

Asimismo, hace inteligibles las trayectorias de las mujeres en comparación con las de los hombres de su familia, considerando que ellas han tenido que volverse fuertes ante las condiciones adversas. Estar acostumbradas a las situaciones difíciles, según Inamabari, generaría cierto aprendizaje a través del cual la trayectoria familiar de estas mujeres se reconstruye. Encontramos en esta narrativa, entonces, un discurso herético, pues la entrevistada explica las crisis objetivas que han tenido que atravesar las mujeres de su familia y las asocia a una competencia crítica que se va acumulando generación tras generación:

Porque a los que son machirulos les va hasta el culo, a los que son violentos [...] En cambio las mujeres estamos logrando cosas, visiblemente, materialmente, y emocionalmente estamos más unidas que nunca. Ah la, las mujeres 
de mi familia somos lo mejor, somos lo mejor que tiene mi familia de verdad. Los hombres son más violentos, estúpidos. Todo les sale mal, no pueden querer a sus hijos, sus hijos los odian, tienen que irse a otro país para hacer algo importante. En cambio, nosotras, o sea las mujeres de mi familia, las dos, mi tía y mi mamá, son madres solteras (Inamabari, 22 años).

Así, vemos que se relata este primer momento de la ruptura herética respecto de las narrativas tradicionales de feminidad. Se plantea que las mujeres pueden atravesar barreras familiares y socioeconómicas a través de la competencia crítica acumulada en el paso de abuelas a madres. Sin embargo, en el paso de madres a hijas se genera un segundo momento de ruptura herética, asociada a cómo Inamabari concibe sus relaciones sexoafectivas:

Creo que mi mamá, yo estoy segura que mi mamá ha decidido una vida muy parecida a la que yo voy a tener solamente que el feminismo no le llegó, no le llegaba a ella de la forma en la que me ha llegado a mí, porque ella siempre critica el machismo en su trabajo en el día a día [...] o el hecho que haya preferido estudiar, trabajar, viajar... yo creo que son decisiones que yo también voy tomando ahora ¿no? incluso más o menos a la misma edad que mi mamá. [...] Pero hay justo un punto en el que parece tan importante en nuestras vidas, cómo son las relaciones y la sexualidad en el que no estamos para nada de acuerdo, que hace que todo parezca que somos como el agua y el aceite, pero ya en verdad siento que somos muy parecidas, solo que en ese punto no. (Inamabari, 22 años).

En ese fragmento, Inamabari destaca las coincidencias entre ella y su madre, pues señala que ambas han tomado decisiones profesionales en una misma línea, y que tienen críticas al machismo en ese tipo de espacios. Sin embargo, existe una distancia importante en la manera como conciben y despliegan su cuerpo y sexualidad. Ella da inteligibilidad a esta diferencia debido a que pudo conocer el feminismo en la universidad, a través del cual se cuestiona discursos sobre la sexualidad que su madre le había transmitido. Es decir, si bien la abuela y la madre pudieron quebrar ciertos patrones de la feminidad tradicional, relacionados sobre todo con el trabajo y la esfera pública, Inamabari aún encuentra resistencia en relación con su cuerpo y su sexualidad. En ese sentido, vemos que el discurso herético sigue generándose. No es, pues, una narrativa estable, sino que parte de crisis objetivas y competencias críticas que se van acumulando. Por ello, cuando se le pregunta por la mejor decisión que ha podido tomar, ella destaca su decisión de estudiar una especialidad que le permita entender y cuestionar su entorno, así como entenderse. 
Estudiar acá $[\ldots]$ porque tranquilamente, probablemente, hubiera estado, no sé... o sea yo sé que no soy tan normal como mi familia quiere que sea, no soy pero esas cosas raras que yo tenía o esas cosas incoherentes que no parecían muy normales las comprendí y las hice mucho más chéveres acá en la universidad y estudiando la carrera que estoy estudiando (Inamabari, 22 años).

En el caso de Mayra, también encontramos un continuum por línea materna. En primer lugar, en el paso de la abuela a la hija, Mayra narra quiebres importantes. Ella destaca la importancia de la independencia económica como posibilitadora de trayectorias biográficas diferentes. En ese sentido, señala que su abuelo engañaba a su abuela, y el motivo que ella encuentra para que esto haya sucedido es la ausencia de independencia económica:

Creo que el no tener la independencia económica, ¿no? O sea, sí y no, ella siempre decía «qué iban a decir», y era una mujer pobre, que no tenía educación, con dos hijos, de hecho a mi abuela la perseguían los doctores para que se operara, era una mujer con muchos hijos, en general, y la menospreciaba por eso. Mi abuela ha sido una mujer muy luchona que ha tenido que trabajar mucho por sus hijos hasta donde ha podido, porque no tenía una educación. Mi abuelo tampoco, se quedó en tercero de secundaria. Por eso para mi abuela, la diferencia entre mis tíos y mi mamá, que sí han podido tener una casa, construir, viajar, ha sido porque mis tíos y mi mamá han tenido que sobrepasar cosas, ¿no? O sea hacerse adultos muy rápido (Mayra, 23 años).

Mayra describe las crisis objetivas que su abuela atravesó en relación con la posición de clase y el género. Destaca el esfuerzo que realizó su abuela, el cual permitió que sus hijos - es decir, la madre y los tíos de Mayra - hayan podido acceder a cierta estabilidad económica luego de trabajar en su juventud. Con respecto a los esquemas de género, Mayra destaca un quiebre en la relación entre su abuela y su abuelo en comparación con la de su madre y su padre. Aunque señala que este quiebre no siempre se nombró, sí se evidenciaban estas diferencias. Recordemos que Bourdieu señala que el discurso herético es también un enunciado performativo que legitima lo que anteriormente se pensaba fuera del sentido común:

De hecho, mi mamá y yo nunca hemos hablado sobre violencia. A mí me hubiese gustado que mi mamá un día me cuente algo sobre eso, yo sé que mi abuelo era muy machista, ahora está súper viejito, pero cuando era joven sí era. Hasta ahora mi abuela se desvive, obliga a mis tías y primas a que le cocinen. Mi abuelo no cocina, y es súper descabellado porque yo sí he visto cocinar a mi papá. Es como que «no es un bebé, no es un niño», pueden cocinar, lavar (Mayra, 23 años). 
La entrevistada, entonces, destaca estos quiebres reconociendo, también, la importancia que su madre daba al trabajo en y por la familia. En ese sentido, relaciona las representaciones de movilidad social a las de maternidad, al señalar que mediante su labor económica «ha dado mucho por su familia». Mayra, entonces, reflexiona sobre ello, ejerciendo una competencia crítica acumulada, y señala que su madre ha tenido una doble carga al ser madre y trabajadora a la vez

En mi casa, en general, supongo que porque les ha costado demasiado, porque han tenido que trabajar mucho, por eso en mi casa ha sido muy de «tenemos todos que trabajar, que aportar a la casa». Mi mamá quizás ha querido hacer más de lo que ha estado en sus manos, pero siempre ha sido una mujer, hasta que falleció, que ha dado mucho por su familia, ídolo de madre, lo que podríamos decir ahora «supermamá", ¿no? y». Y súper doble forma de oprimir, cumple ser mamá y ser trabajadora, en una sociedad donde si trabajas, no es tan buena mamá, y viceversa. En mi casa es un deber trabajar (Mayra, 23 años).

Vemos, entonces, que se va desarrollando un discurso herético al darse las dos condiciones para ello. La crisis objetiva se presenta respecto de la doble labor que significa realizar trabajos de provisión y de cuidado. Así también, el discurso crítico acumulado indica la posibilidad de cambiar trayectorias de vida con relación al género a través de la movilidad social. Este discurso herético se va transmitiendo a través de las narrativas de feminidad en la línea materna:

Mi mamá trabajaba en mi casa, entonces era súper así, por eso, mi mamá siempre me decía que yo tenía que tener. Que si tenía mi pareja, tú tienes que tener dinero. Ella me decía, bromeándome, «imagínate que estés con tu regla y no tengas para tu toalla higiénica, y le tengas que pedir a un hombre para que te dé plata, eso no puede pasar, Mayra', mi mamá me decía.Mayra». Está bien, le decía, eso no va a pasar [...] Mi mamá siempre decía que trabajar no era malo, que nunca me iba a hacer daño. Aparte, mi mamá me decía que siendo mujer la única forma que yo salga adelante en un mundo, tan así como el nuestro era que yo trabajara, de hecho yo creo eso, también, en una sociedad tan machista, por desgracia, las mujeres tienen que ganar un sustento económico. Es la forma en la que las mujeres tienen que ganarse un espacio de respeto, cosa que no debería pasar, porque no todos los hombres trabajan y no se les deja de respetar. Eso sí, a mí, para mí, era como muy importante [...] Yo creo que mi mamá me enseñó un montón de cosas a mí también, o sea, a valerme por mí misma, a ser fuerte, independiente, a su manera, también (Mayra, 23 años). 
De esta manera, vemos cómo se relaciona la independencia económica con una posible autonomía en las relaciones de pareja. Este discurso herético surge cuando se pregunta a Mayra sobre lo que le decía su madre para cuando ella fuera adulta. En este fragmento, vemos, en principio, cómo se siguen reproduciendo discursos típicos ligados a la feminidad, como el pudor que la menstruación debería causar o la pareja heterosexual, pero también que se relaciona esta feminidad a una ineludible autonomía económica, pues no es deseable pedirle a un hombre para resolver sus necesidades. Asimismo, señala que la posición de las mujeres en la estructura actual las obliga a tener que ganarse un espacio de respeto a través del trabajo. Esto se refleja también en la distinción que Mayra —así como Inamabari- realiza de sus familiares mujeres y hombres:

Y yo tengo varias tías solteras, y pero, también tengo tías madres solteras, a la que mis tías le han apoyado, y siempre fue así. O sea no sé, aparte las mujeres de la familia de mi mamá son mucho más conscientes.

— ¿Cómo así?

No sé, por ejemplo, mis primos hombres no son preocupados por su vida. En cambio mis primas siempre sobresalen. Las mujeres de mi familia siempre han sobresalido. Mis primos hombres son muy dejados, no estudian, los han puesto a estudiar y no quieren (Inamabari, 22 años).

Así, esta independencia económica para la reconfiguración en las feminidades y las relaciones de género constituye la primera etapa de la ruptura herética.

Ahora bien, en el paso de madre a hija aparece el tema del despliegue del cuerpo y la performance de género, que articula un segundo momento de ruptura herética:

O sea yo creo, mi mamá nunca me dijo como..., o sea, de hecho me decía «tienes que ser más limpia, como una mujer», esas frases, pero aparte de esa no, hasta que una vez hablamos del acoso, pero ya grande. O sea mi mamá nunca ha intentado darme una idea fija, pero sí íbamos a la iglesia, mi mamá era muy creyente, era mormona, y ahí sí me decían cómo tenía que ser, o sea, que tenía que ser así, que no tenía que tener novio. No me lo decía mi mamá, pero me lo decía la iglesia. Y de hecho yo dejé de ir a la iglesia porque yo hacía karate los domingos, y hacía más karate para no ir. Y yo iba con tacos y falda a la iglesia, pero no me gusta, me sentía muy incómoda, porque sentía que no podía ser yo, no puedo correr. Y mi mamá siempre ha sido, no me ha impuesto una idea, pero sí me ha llevado a lugares. Creo que esa era la forma en la que no mi mamá, sino la sociedad, me imponía (Mayra, 23 años). 
En esta cita, Mayra relata que, si bien su madre la instaba a ser más limpia por ser mujer, o a vestirse de una manera determinada para ir a la iglesia, no sintió una presión agobiante con respecto a las representaciones de feminidad que manejaba. La entrevistada entiende a su madre a través de lo que escuchó de su abuela:

Yo creo también que, que tu mamá no es que sea mala, sino que mi mamá ha tratado mucho de cuidarme porque mi abuela también me decía «tu mamá era súper tosca cuando era niña, jugaba con tus tíos, que eran hombres». Mi mamá no era tan femenina, de hecho, no se pintaba hasta que creció, se hizo adulta, a los treinta y tantos. De hecho, yo también he sido así, y ahora recién a los veintitantos me puedo pintar (Mayra, 23 años).

Como señalan Arango y Molinier (2011), el ejercicio del cuidado aparece ante la posibilidad del riesgo. En este caso, Mayra da inteligibilidad a las narrativas de feminidad que tiene su madre señalando que ella misma ha experimentado el riesgo que significa representar ciertas performances de género diferentes de las tradicionales, como la exclusión entre pares. En ese sentido, Mayra encuentra puntos en común con la feminidad con la que ella actualmente se identifica. Sin embargo, la crisis objetiva se evidencia en el despliegue del cuerpo en la entrevistada, pues señala que durante la adolescencia no se sentía segura de este, debido principalmente al acoso callejero:

O sea, para mí, el acoso, superar el tema del acoso fue como más de un año, el ser consciente, el hablarlo, y el apoyar el tema, como dos años. Y luego de eso tuve mucha más seguridad en la calle, ser más fuerte, o sea, ser una persona mucho más extrovertida que antes. O sea, igual de callada y reservada en mis cositas, pero más extrovertida. No hablábamos tanto de eso, más sobre qué tenía que estudiar, esas cosas. O sea mi mamá, el tema de cómo ser mujer no era más que ser señorita y que me molestaba por ser limpia. Pero no era como otras mamás, incisivas que algunas de sus amigas de universidad eran muy incisivas con sus hijas, en cambio mi mamá no era tanto. A veces evitaba llevarme para que sus amigas no me vieran, porque yo sentía que me miraban (Mayra, 23 años).

En ese sentido, el tema no era conversado, y lo que narra Mayra es que, en cambio, hablaban sobre temas relativos a seguir estudiando. Así, se fue acumulando una competencia crítica que posteriormente devino experiencias de género más acordes a lo que Mayra sentía. Para ello, es clave la entrada a la universidad y el feminismo:

Sí, de hecho esa ha sido una de las cosas que más me impactó siempre, y de hecho porque yo inicié siendo feminista por eso, por el tema del acoso [...] 
Sí pues, es complicado, de hecho mi mamá me decía que me cuide. Es que yo tenía amigos hombres, yo era muy cuidada por los chicos... Más bien el feminismo me ha dado feminidad, también [...] Yo cuando entré a la universidad era súper masculina, si no hubiese sido porque tenía tetas y trasero, no parecía mujer, como hablaba, era muy ruda. Yo me he criado en un mundo muy varonil, mi papá me ha enseñado a ser muy fuerte. Y entendía los chistes de los hombres, y eso que estudiaba en un colegio de mujeres, pero solo tenía una amiga mujer que tampoco era tan femenina, como yo, de hecho ella me enseñó a ser femenina (Mayra, 23 años).

Vemos que existe un mayor margen para una feminidad diferente al encontrar nuevos espacios y sentirse más segura sobre sus performances de género. El discurso herético sigue entonces configurándose, pues las posibles crisis objetivas aparecen y la competencia crítica se va acumulando.

En los casos de Sofía y Madel, ellas tienen narrativas sobre la movilidad social similares por la línea materna. En ambos casos ellas expresan las crisis objetivas que sus madres experimentan al querer cambiar de entorno, así como la competencia crítica que plantean frente a sus familias o sus pares por evidenciar estos deseos. Cuando se pregunta a Sofía sobre la importancia que su madre daba a la universidad, ella señala:

Mi mamá estudiaba porque no quería ser como los de su barrio, borrachos, sucios, flojos, sin aspiraciones... yo veía la diferencia entre mis tíos que no habían estudiado, no había tema de conversación sobre la mesa, hablaban de una sola cosa; por eso mi mamá me decía: «Hijita, tú tienes que saber cosas de todos lados, tú tienes que estar preparada» (Sofía, 21 años).

De esa manera, se liga este quiebre en la trayectoria familiar con una movilidad social desde una dimensión cultural. En el siguiente fragmento se hace referencia también a un cambio en la trayectoria biográfica, pero relacionada directamente con las narrativas de feminidad:

Ver a mi mamá tan fuerte que iba en contra de un culo de cosas, como divorciarse, estar con otro hombre, que sea menor, con dos hijas, ¿manyas? y todo el mundo está en contra, no le parecía, ver a mi mamá que se la jugó. Ella decía yo tengo que ser ejemplo de mis hijas de felicidad, si yo no soy feliz, ellas van a creer que no ser feliz está bien, y yo quiero que sean felices (Sofía, 21 años).

Sofía resalta el quiebre no solo en el aspecto económico, sino la competencia crítica sobre la maternidad. A diferencia de feminidades tradicionales, se piensa la 
separación de los padres como un cambio positivo, pues la madre lo decide como parte de su competencia crítica, tejiendo estrategias de resistencia. La frase «ver a mi mamá que se la jugó» refleja esta valoración positiva de este cambio, que representa un quiebre no solo a nivel biográfico, sino también en lo imaginado sobre lo que es ser una «buena mujer».

Por otro lado, en el caso de Madel, ella resalta el cambio que su madre impulsó en la trayectoria familiar, el que incluso fue denostado por sus hermanos:

O sea, eh, mi mamá siempre tuve bien claro, y ella lo cuenta, de que quería salir de ahí, que no tenía amigos en el barrio, no veía que podía sacar algo bueno de hacer amigos ahí, pero algo que ella le critica a mis hermanos es que ellos no hayan sido tan así, ¿no? Que la veían a ella como la aburrida de «por qué solo estudias o por qué solo trabajas, por qué no te juntas con la gente de acá, qué cosa te crees, que por qué haces eso, tú eres igual que ellos». Su mamá le decía eso, mi abuela decía: «Hijita, pero tú eres pobre, por qué eres así»». Pero no sé, mi mamá quería hacer cosas, quería estudiar, este, bueno, parece que tampoco había buenas juntas con mis tíos, o sí, no, no sabía, estaban en esas dudas de salir del cole y no saber qué hacer, de repente trabajar, no trabajar, en qué trabajar, si estudiar o no, estudiar tampoco no era tanta la opción, ¿no? (Madel, 22 años).

Madel describe que su madre siempre tuvo claros sus deseos de movilidad social, y que estos no fueron compartidos necesariamente por sus hermanos o su abuela. En la actualidad, estos proyectos de movilidad social a través del trabajo y los estudios son muy valorados por ella. Sin embargo, tiene también su propia lectura de estos procesos: hace poco, se le detectó a su madre cáncer de mama, y ella entiende que esta enfermedad se relaciona con el poco tiempo que pasó con sus hijos de pequeños. En este caso, las narrativas de feminidad ligadas a la movilidad no son armónicas. Sin embargo, la entrevistada también señala que no había otra alternativa para sostenerse económicamente. Así, cuando se le pregunta por el mayor reto que su madre ha afrontado, ella señala:

Hace un par de meses le detectaron cáncer de mama mi mamá [...] Pero mi mamá cree mucho en esta cuestión de las raíces sociales de las enfermedades y una de las cosas que ella cree es que le ha dado por no haber pasado tanto tiempo con nosotros [...] Entonces ese es un proceso de curación emocional. No quiere hacerse quimios ni nada [...] Y si no hubiese sabido esto, si me preguntabas algo sobre mi mamá, hubiese respondido lo mismo: el alejarse de nosotros fue muy duro para ella y para nosotros. El tener que salir y trabajar fuera para que la casa se mantenga cuando mi mamá no ganaba más de mil lucas en un periódico, no había..., ¡en la vida iba a alcanzar para vivir! (Madel, 22 años). 
En ese sentido, Madel describe lo duro que fue para su familia que la madre haya tenido que tomar la decisión de pasar menos tiempo con sus hijos para conseguir mayor provisión económica. Ella alega que no había otra alternativa si querían tener otro estilo de vida, con relación a sus proyecciones. La entrevistada se sitúa a sí misma como parte de un continuum familiar en el que es importante la reflexión y la formación intelectual. Asimismo, enfatiza la trayectoria y la movilidad que su familia materna y paterna ha desplegado a lo largo del tiempo, sobre todo a través del capital cultural acumulado.

En el caso de Camila, se visibilizan más claramente los quiebres en la línea materna que permean en roles de género. La entrevistada valora las crisis objetivas que las mujeres de su familia han tenido que afrontar, sobre todo porque muchas de ellas son madres solteras y han realizado labores de provisión y cuidados al mismo tiempo. Por ello, ella señala que las mujeres de su familia han tenido que ser fuertes, y aunque poseen autoridad en la casa, administrando y organizando los recursos, eso no las ha eximido de experimentar violencia y actitudes machistas:

O sea, también son un toque machistas, pero es por el ámbito en el que han vivido. Pero como te digo, las mujeres de mi familia son fuertes. Ellas todas son las que prácticamente... yo he vivido en matriarcado, en realidad siempre hemos vivido en un matriarcado. O sea, las mujeres de mi casa son las que han sacado adelante a sus hijos, prácticamente solas [...] (Camila, 22 años).

Camila explica que esta fortaleza o autonomía de las mujeres de su familia en realidad no ha sido completa, pues la entrevistada señala el fuerte mandato hacia la fidelidad en las parejas. Incluso hace un paralelo entre esta manera de vivir las relaciones de pareja y soportar el dolor físico.

Pero como te dije, la maldición de mi familia en las mujeres de mi casa que yo tengo, que yo tenía miedo, es que son mujeres de un solo hombre, son muy leales ante un solo hombre [...] Son de un solo hombre... son muy fuertes, muy aguerridas. Tanto que aprendí que en mi familia es así de «muérete en tu casa». Así haya dolor, ya cuando estés agonizando, ahí te llevamos al hospital. O sea así fue mi familia, entonces, son así, son muchos ¿no? Saben trabajar. O sea para ellas no es como que, no, de que «alguien me debe mantener». No, ellas trabajan desde siempre, desde siempre, pero eso del amor romántico... es una maldición (Camila, 22 años).

En ese sentido, identifica las ideas de amor romántico con las que se ha familiarizado, y teme reproducirlas. En ese sentido, siente que es la manera en que experimenta la crisis objetiva de las relaciones sexo-género: la dependencia de 
pareja. Aunque también se manifiesta cierta competencia crítica al evidenciarla e intentar quebrarla.

La maldición, maldita sea, por eso ya tengo miedo. Yo digo no, no quiero estar con más gente, tengo que romper eso, no puede ser, no puede ser posible. Y así son las mujeres de mi familia, de un solo hombre, por eso es como que como te digo, a mí el patriarcado me ha afectado ya de grande, porque he visto la realidad del patriarcado y cuando ya he salido de mi burbuja, pero lo que sí me ha afectado desde siempre ha sido el amor (Camila, 22 años).

Sin embargo, relata que gran parte de su personalidad se debe a la crianza de su madre, quien, según Camila, ha querido romper, a través de ella, con ciertas inseguridades que ha experimentado.

Yo era mandona, yo siempre digo: el problema del machismo y patriarcado o sea sí lo he sentido de chibola. Pero a mí no me ha impactado tan fuerte esa huevada y es gracias a mi mamá, porque como mi mamá era bien temerosa, como te digo, me dice que su hija no quería que sea nada absolutamente nada de lo que era ella cuando era chibola, que lloraba a cada rato, que no hablaba, cero. Entonces mi mamá, desde chibola, ya me ha formado con mucha seguridad, por eso es que soy una desgraciada hasta ahora, ya tengo mucha seguridad en algunos aspectos (Camila, 22 años).

En este fragmento, destaca el afán de ruptura que su madre plasma en la manera de criar a su hija. Camila se siente parte de esta ruptura herética compartida con su madre. Asimismo, destaca que su seguridad personal se debe a las narrativas que compartían su madre en el espacio familiar sobre el mundo externo. Estos juicios de valor y diversas experiencias posibilitaron sus marcos de referencia sobre las feminidades.

\section{CONCLUSIONES}

En este artículo se ha descrito y analizado la manera en que la representación de la madre tiene relación con las feminidades de las entrevistadas. Las trayectorias biográficas de estas mujeres con relación a sus madres presentan quiebres en torno a las posibilidades académicas y laborales, así como las representaciones sobre el cuerpo y la sexualidad. Se presentaría una especie de sincretismo de género (Lagarde, 2000) en el que se genera una identidad a partir de las tensiones entre lo tradicional y lo moderno. No obstante, estas transformaciones forman parte de un continuum familiar por línea materna, en el que sus abuelas y madres han ido 
transformando previamente sus contextos particulares. Las relaciones de género en una clase media recientemente consolidada se encuentran en transformación constante, pues las representaciones de las mujeres, así como las prácticas que se originan en los diversos espacios de socialización, son constantes espacios de disputas de recursos materiales y simbólicos. Estos espacios de disputa se relacionan con la apropiación de la esfera pública, como la universidad y el mercado laboral, así como la esfera privada, relacionada con el cuerpo, la maternidad y la sexualidad.

Así entonces, se generan las condiciones para la configuración de un discurso herético. Este se genera cuando coincide la crisis objetiva, relacionada con la transformación de las experiencias de género y las necesidades de movilidad social, junto a la competencia crítica. Esta se va acumulando a través de cada generación y significa un quiebre en los marcos de posibilidades anteriores. Así, distinguimos también dos momentos de ruptura herética. El primero que rastreamos se distingue en el paso de abuelas a madres, en el que resalta la independencia económica como posibilitadora de nuevas trayectorias biográficas, relacionadas con nuevos esquemas en los roles de género y la autonomía como mujeres. En el segundo momento, se distingue el paso entre madres a hijas, y las narrativas de feminidad se constituyen a través de las crisis objetivas y la competencia crítica acumulada. En esta etapa, la crisis objetiva se evidencia en el despliegue del cuerpo y la sexualidad, la cual se experimenta sin un marco de referencia estable. Existen muchas tensiones alrededor de esta, pero se genera un discurso crítico en la línea de las nuevas narrativas de feminidad.

Entonces, a través de estas nuevas narrativas de feminidad, condensadas a través de los discursos heréticos, se enfrentan las otras desigualdades adscritas y adquiridas.

\section{REFERENCIAS}

Arango, Luz Gabriela (2002). Sobre dominación y luchas: clase y género en el programa de Bourdieu. Revista Colombiana de Sociología, 1(7). Bogotá, 99-118.

Arango, Luz Gabriela y Pascale Molinier (2011). El cuidado como ética y como trabajo. Bogotá, D.C.: La Carreta Editores. Universidad Nacional de Colombia.

Arellano Marketing (2015). Un mercado creciente: descubriendo oportunidades en la base de la pirámide en Perú. Lima: Banco Interamericano de Desarrollo 
Bourdieu, Pierre (1999). La miseria del mundo. Buenos Aires: Fondo de Cultura Económica de Argentina.

Bourdieu, Pierre (2001). ¿Qué significa hablar? Economía de los intercambios lingüisticos. Madrid: Akal.

Brunet, Ignasi y Alejandro Pizzi (2013). La delimitación sociológica de la juventud. Última Década, 11-36.

Butler, Judith (2007). El género en disputa. Barcelona: Paidós.

Dalle, Pablo (2016). Movilidad social desde las clases populares. Un estudio sociológico en el Área Metropolitana de Buenos Aires (1960-2013). Buenos Aires: Clacso y Facultad de Ciencias Sociales de la UBA.

Flick, Uwe (2007). Introducción a la investigación cualitativa. Madrid: Elecé.

Fuller, Norma (1998). Dilemas de la feminidad. Mujeres de clase media en Perú Lima: Pontificia Universidad Católica del Perú. Recuperado de http://www.academia. edu/701089/Dilemas_de_la_femineidad

Lagarde, Marcela (1990). Los cautiverios de las mujeres: madresposas, monjas, putas, presas y locas. México, D. F.: UNAM.

Lagarde, Marcela (2000). Claves feministas para la autoestima de las mujeres. Madrid: Horas y Horas.

Lipovetsky, Gilles (1999). La tercera mujer. Permanencia y revolución de lo femenino. Barcelona: Anagrama.

Martínez-Salgado, Carolina (2011). El muestreo en investigación cualitativa. Principios básicos y algunas controversias. Artigo Article, 613-619.

Pajuelo, Ramón (2002). El lugar de la utopía. Aportes de Aníbal Quijano sobre Cultura y Poder. En D. Mato, Estudios y otras prácticas latinoamericanas en cultura y poder. Caracas: CLACSO, Consejo Latinoamericano de Ciencias Sociales

Pariona, Tania (2016) Postergación de la maternidad en mujeres profesionales residentes en Lima. Tesis de maestría en Antropología. Lima: Pontificia Universidad Católica del Perú.

Reygadas, Luis (2008). La apropiación: destejiendo las redes de la desigualdad. México, D. F.: Anthropos.

Rivera, Cecilia (1993). María marimacha: los caminos de la identidad femenina. Lima: Fondo Editorial PUCP.

Ruiz-Bravo, Patricia (1995). Estudios, prácticas y representaciones de género. Tensiones, desencuentros y esperanzas. En G. P. Valcárcel, El Perú frente al siglo XXI (pp. 441-468). Lima: Fondo Editorial PUCP. 
Solís, Patricio (2016). Movilidad intergeneracional de clase en América Latina: una perspectiva comparativa. En P. Solís y M. Boado, $Y$ sin embargo se mueve... (pp. 75-132). Ciudad de México: El Colegio de México y Centro de Estudios Espinosa Yglesias.

Toche, Eduardo (2009). Apuntes sobre las clases medias. En Perú Hoy (pp. 143-162). Lima: Desco.

Zea, Mayra (2015). Mujeres policías: Representación de la femineidad en la construcción de la identidad de 1980 a la actualidad. Tesis de licenciatura en Sociología. Lima: Pontificia Universidad Católica del Perú. 